
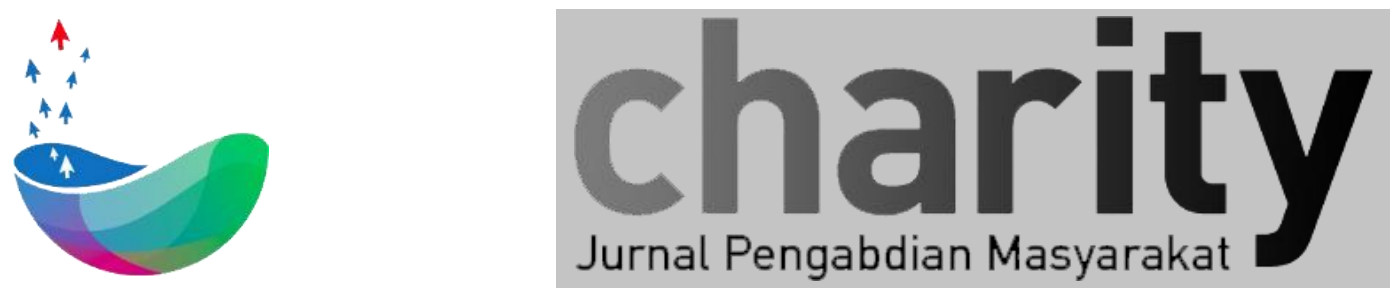

\title{
WORKSHOP DAN PELATIHAN PEMBUATAN E-KATALOG SEBAGAI MEDIA PENJUALAN ONLINE DAN CLOUD APPLICATION UNTUK UMKM SAAT WFH COVID-19
}

Arry Widodo ${ }^{1}$, Candra Wijayangka ${ }^{2}$, R. Nurafni Rubiyanti ${ }^{3}$, Ade Irma Susanty ${ }^{4}$, Anita Silvianita ${ }^{5}$, Romat Saragih ${ }^{6}$, Gita Indah Hapsari $^{7}$, Prajna Deshanta Ibnugraha ${ }^{8}$, Mia Rosmiati ${ }^{9}$

${ }^{1}$ Fakultas Komunikasi \& Bisnis/Administrasi Bisnis/ Universitas Telkom

${ }^{2}$ Fakultas Komunikasi \& Bisnis/Administrasi Bisnis/ Universitas Telkom

${ }^{3}$ Fakultas Komunikasi \& Bisnis/Administrasi Bisnis/ Universitas Telkom

${ }^{4}$ Fakultas Komunikasi \& Bisnis/Administrasi Bisnis/ Universitas Telkom

${ }^{5}$ Fakultas Komunikasi \& Bisnis/Administrasi Bisnis/ Universitas Telkom

${ }^{6}$ Fakultas Komunikasi \& Bisnis/Administrasi Bisnis/ Universitas Telkom

${ }^{7}$ Fakultas Ilmu Terapan/ D3 Teknologi Komputer / Universitas Telkom

${ }^{8}$ Fakultas Ilmu Terapan/ D3 Teknologi Komputer / Universitas Telkom

${ }^{9}$ Fakultas Ilmu Terapan/ D3 Rekayasa Peragkat Lunak Aplikasi / Universitas Telkom

*arrywie@telkomuniversity.ac.id

INFO ARTIKEL

Diterima 10 Juli 2020

Direvisi 09 Februari 2021

Disetujui 18 Desember 2021

Tersedia Online 4 Februari 2022

\begin{abstract}
ABSTRAK
Tujuan dari pengabdian masyarakat ini adalah untuk memberikan pengetahuan kepada pelaku bisnis terutama UMKM (Usaha Mikro Kecil dan Menengah) dalam meningkatkan bisnis yang mereka jalani. Setiap perusahaan yang profesional harus memiliki strategi penjualan, terutama di tengah wabah Covid-19. Strategi ini dibutuhkan sebagai bentuk pertanggungjawaban perusahaan dan untuk mengukur kemampuan perusahaan untuk bertahan. Untuk itu, diperlukan strategi penjualan melalui E-Katalog pada media online, serta penggunaan cloud computing sebagai pusat pengelolaan data. Penggunaan teknologi ini harus mudah dipahami oleh pihak yang berkepentingan. Selain itu juga harus relevan artinya bisa digunakan oleh pelaku bisnis UMKM. E-Katalog tersebut juga harus andal, yaitu dapat digunakan terus-menerus sehingga dapat digunakan untuk meningkatkan penjualan, tidak hanya di tengah kondisi wabah. Hasil yang diharapkan adalah masyarakat sasar dapat membuat E-Katalog sederhana, sehingga mampu bertahan di tengah kondisi bisnis saat ini dan dapat meningkatkan kompetensi masyarakat di masa depa
\end{abstract}

Keyword: E-Katalog, Media Online, UMKM

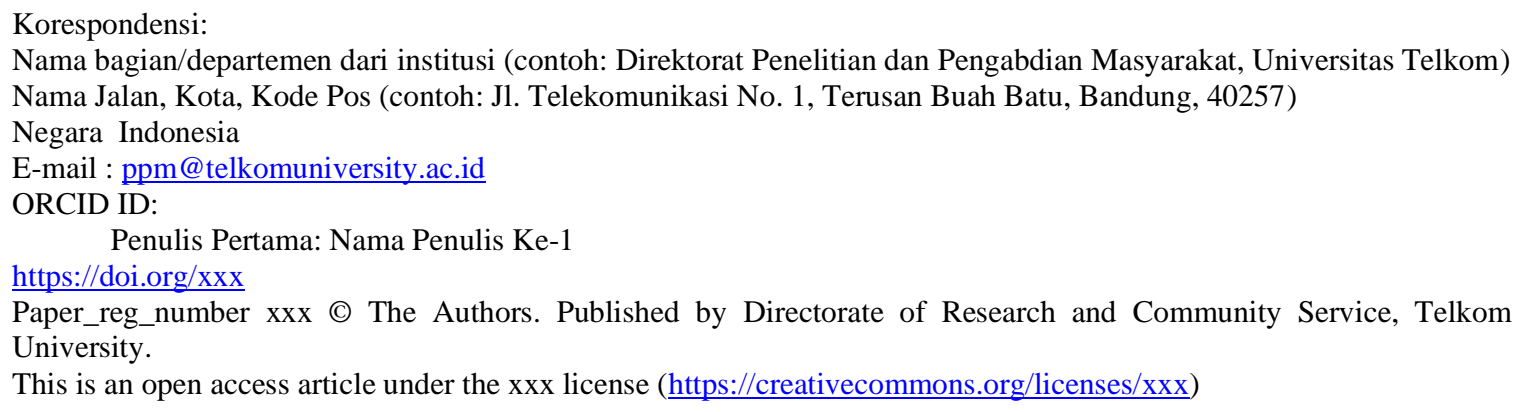




\section{PENDAHULUAN}

Paguyuban Pengusaha Kecil dan Menengah (PPKM) Kab.Bandung dibentuk pada tanggal 25 Januari 2017 di Gedung Moh. Toha PEMDA Soreang. PKM dibentuk dengan keinginan bersama untuk membuat wadah yang menjadi ajang silahturahmi dan bersinergi. Sehingga bisa menjadi kuat karena bersilahturahmi, maju karena bersinergi dan bersama-sama dalam kemandirian. Paguyuban Pengusaha mengelola 300 UMKM yang tersebar di 31 Kecamatan seKabupaten Bandung dengan berbagai jenis usaha.

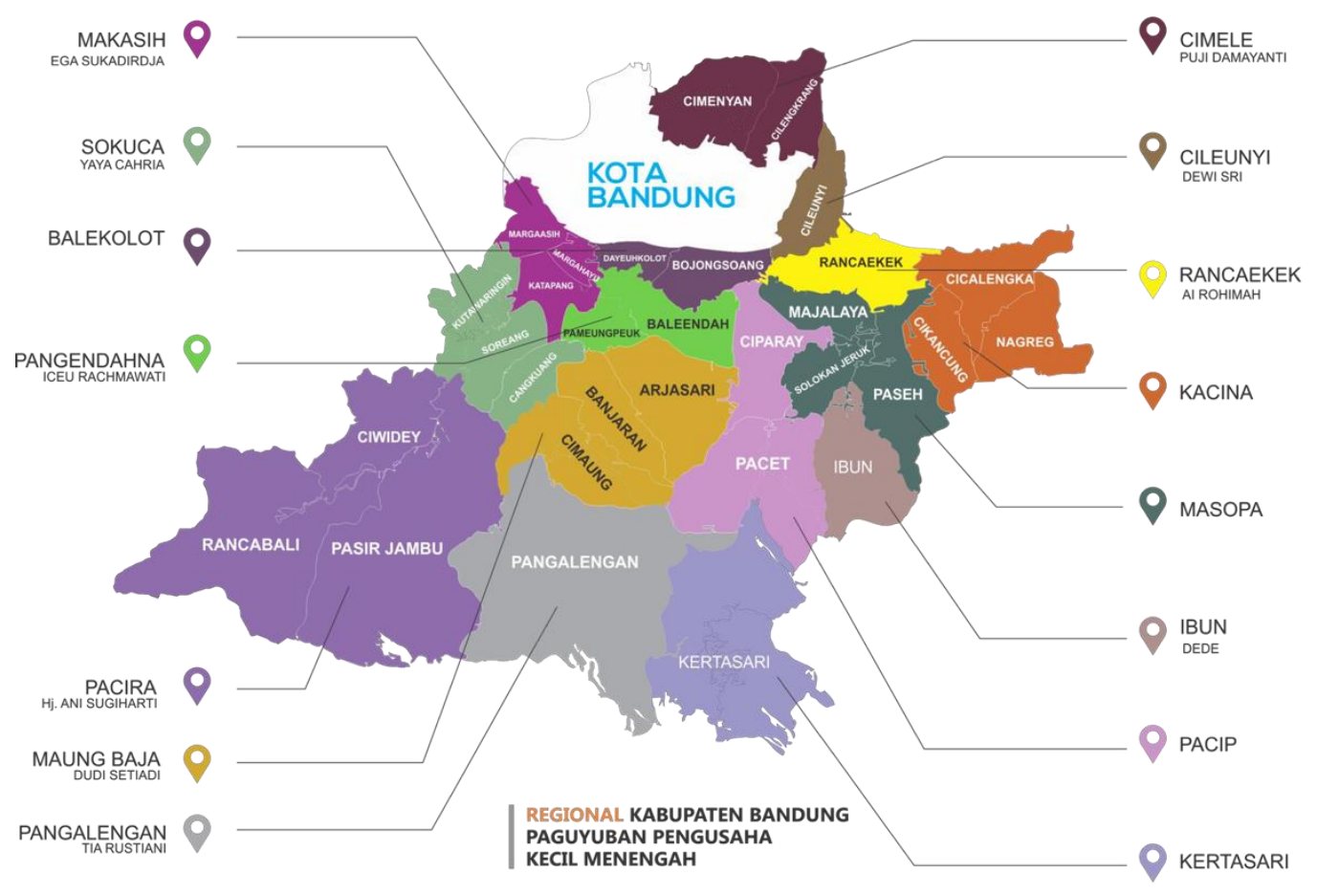

Gambar 1.

Daerah Binaan PPKM 
Adapun jenis usaha yang menjadi anggota dari PPKM sebagai berikut:

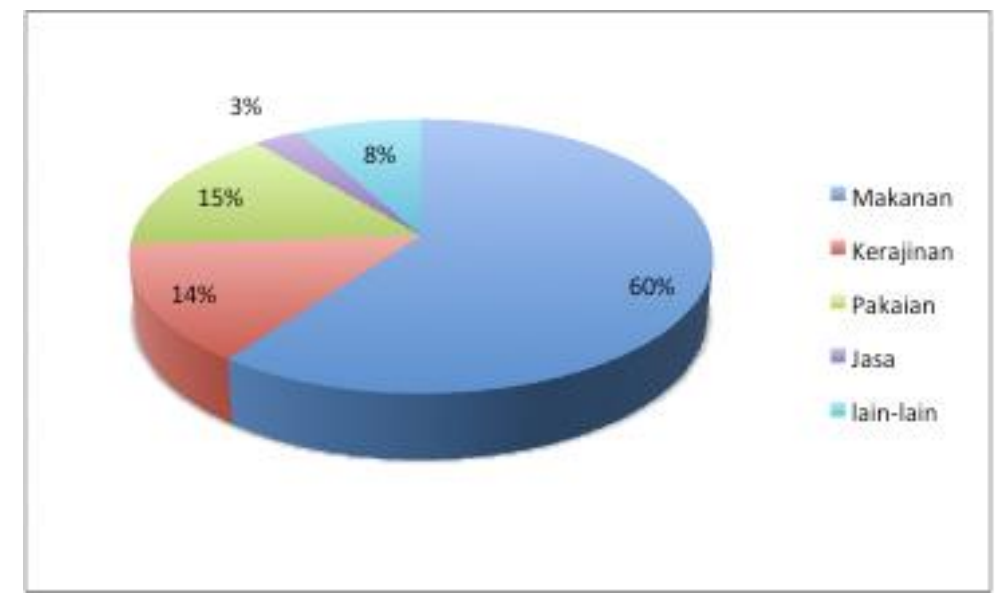

Gambar 2

Jenis Usaha PPKM

PPKM ini didominasi oleh Pengusaha Makanan baik kemasan ataupun non kemasan, diikuti dengan kerajinan, pakaian dan Jasa.

\section{PERMASALAHAN}

Permasalahan yang ditemukan selama proses survei ke lokasi dalam pelaksanaan pengabdian masyarakat ini adalah;

1) Salah satu sektor yang terdampak cukup berat saat terjadinya Wabah COVID-19 adalah di UMKM. Banyak UMKM yang akhirnya harus merumahkan karyawan ataupun tutup usaha akibat wabah COVID-19.

2) UMKM harus pandai melihat peluang usaha meskipun ada pembatasan aktivitas di luar rumah.

3) Kurangnya pemanfaatan transaksi serta proses bisnis seperti marketing online, pengelolaan proses binis serta pengelolaan karyawan.

\section{METODE PELAKSANAAN}

Adapun metode pelaksanaan kegiatan yang akan dilaksanakan meliputi tahapan sebagai berikut:

3.1. Analisis dan perangcangan aplikasi berbasis web

Adapun proses yang dilakukan untuk:

a. Menggambarkan setiap proses bisnis untuk dievaluasi sehingga diperoleh gambaran lengkap kondisi saat ini dan untuk mengidentifikasi permasalahan yang terjadi; 
b. Mengidentifikasi kebutuhan fungsionalitas sebagai acuan dalam menentukan fitur yang harus dimiliki oleh web site yang dibangun. Perancangan dilakukan meliputi:

- Memodelkan fungsionalitas

- Membuat rancangan database

- Membuat rancangan interface.

3.2. Pembangunan, Pengujian, dan dokumentasi web site

Tahapan ini merupakan tahap pembuat coding program untuk membangun web site berdasarkan rancangan yang telah dibuat; menguji aplikasi untuk memastikan semua fungsionalitas berjalan valid; dan mendokumentasikan web site untuk menghasilkan buku panduan penggunaannya.

3.3. Pelatihan dan sosialisasi

Tahap ini dilakukan untuk melatih semua pengguna agar dapat menggunakan web site dan mensosialisasikannya kepada pihak - pihak yang berkepentingan(seperti dinas pemerintah terkait).

\subsection{Tempat kegiatan dilaksanakan sesuai dengan tahapan yang dilakukan.}

a. Kegiatan dan koordinasi Tim PkM dilaksanakan di Fakultas Ilmu Terapan (FIT) dan Fakultas Komunikasi dan Bisnis (FKB) secara bergiliran. Kegiatan yang dilaksanakan meliputi : diskusi persiapan dan evaluasi capaian kegiatan, pembahasan hasil analisis dan desain aplikasi, serta pengujian aplikasi pada tahap development;

b. Wawancara untuk pengumpulan data Analisa untuk kebutuhan aplikasi;

c. Konfirmasi, persetujuan rancangan, dan pengujian aplikasi dilakukan di Fakultas Ilmu Terapan (FIT) dan Fakultas Komunikasi dan Bisnis (FKB) secara bergiliran (tempat pengujian dapat berubah disesuaikan dengan situasi atau kondisi masa Pandemi Covid19).

d. Pelatihan dan sosialisasi penggunaan web site dan manajemen SDM di laksanakan di Kampus Universitas Telkom. (tempat dan cara pelatihan dan sosialisasi dapat berubah disesuaikan dengan situasi atau kondisi masa Pandemi Covid-19).

\section{ANALISA HASIL KEGIATAN PENGABDIAN MASYARAKAT}

Pelaksanaan pengabdian kepada masyarakat ini melibatkan PPKM (Paguyuban Pengusaha Karsa Mandiri), yaitu Kelompok yang terdiri dari berbagai macam UMKM yang lokasinya berada di wilayah Kabupaten Bandung. Saat ini permasalahan yang dihadapi adalah berkaitan dengan kondisi keadaan pada saat Pandemi Covid-19 serta lebih mempromosikan produk-produk UMKM 
pada PPKM (Paguyuban Pengusaha Karsa Mandiri), sehingga dapat menjadi produk unggulan. Lebih lanjut hasil yang diharapkan menjadi lebih efektif dan efisien dengan memanfaatkan teknologi digital.

Proses kegiatan dari pelaksanaan pengabdian kepada masyarakat, yaitu menjelaskan mengenai pemanfaatan sistem informasi kepada mitra dalam hal ini UMKM yang bernaung dalam PPKM. Sistem informasi adalah kumpulan komponen didalam suatu organisasi yang berfungsi sebagai pengolahan untuk menghasilkan sebuah laporan-laporan yang disajikan kepada pihak tertentu (Sri Handayani, 2016). Dimana sistem informasi merupakan bagian dari sebuah sistem yang dibuat untuk mengolah dari data mentah menjadi sebuah laporan yang berharga, supaya bisa disajikan kepada stackholder yang membutuhkan.

Proses selanjutnya, dilakukan pelatihan dan pemahaman mengenai e-commerce. Pembuatan desain dan perancangan aplikasi e-commerce berbasis website. Dimana dalam pelaksanaannya menggunakan E-Katalog yang akan berguna dan memudahkan bagi pelaku bisnis dan konsumen. Selanjutnya memanfaatkan E- Commerce yang merupakan suatu hubungan antara organisasi atau kelompok bisnis dengan customer, dengan bantuan penggunaan internet dan media website yang digunakan untuk penjualan produk serta melayani customer supaya lebih efektif dan efisien tanpa harus customer datang ke tempat (Shabur, Miftah Maulana, dkk. 2015; Kotler \& Keller. 2016).

Pembeda pada proses jual dan beli produk pada sistem e-commerce dengan proses jual dan beli produk secara tradisional adalah semua proses yang dimulai dari mencari informasi mengenai barang atau jasa yang diperlukan, kemudian melakukan pemesanan dan yang terakhir proses pembayaran di lakukan secara elektronik (Handayani, Sri, dkk. 2016).

Kegiatan pengabdian masyarakat periode ini dilakukan dengan menyediakan aplikasi ecommerce yang dibuat berbasis website. Pengertian website adalah sebuah software yang berfungsi untuk menampilkan dokumen-dokumen pada suatu website yang membuat pengguna dapat mengakses internet melalui software yang terkoneksi dengan internet (Gangeshwer, 2013; Mara Destiningrum, 2017).

Tahapan dari kegiatan ini adalah mendesain sistem secara keseluruhan untuk aplikasi ecommerce. Desain dibuat mulai dari perancangan database dan alur aplikasi yang akan digunakan dan hosing pembuatan website e-commerce dengan alamat www. http://ppkm-org.id/.

Manfaat yang diperoleh perusahaan atau pebisnis dalam kegiatan Abdimas yang melibatkan PPKM (Paguyuban Pengusaha Karsa Mandiri) dengan menggunakan layanan aplikasi e-commerce berbasis website, antara lain sebagai berikut: 
1) Melayani customer tanpa batas waktu; Dengan adanya aplikasi e-commerce memungkinkan customer dapat melakukan proses transaksi jual-beli produk 24 jam nonstop tanpa harus terikat waktu buka ataupun tutup.

2) Mendapatkan customer baru dan mempertahankan customer yang lama tetap bertahan; Dengan adanya aplikasi e-commerce ini, memungkinkan perusahaan atau pebisnis mempertahankan customer yang lama, dikarenakan customer tidak perlu repot datang ke tempat dan pebisnis mendapatkan customer baru, baik itu berasal dari customer lokal, domestik maupun luar negeri.

3) Meningkatkan mutu layanan; Dengan adanya aplikasi e-commerce ini, pebisnis dapat meningkatkan mutu pelayanan dengan melakukan interaksi yang lebih personal dengan customer, dikarenakan aplikasi e-commerce ini dilengkapi contact person yang terhubung langsung dengan admin melalui whatsapp/telepon.

4) Meningkatkan area pemasaran produk PPKM. Karena dengan memanfaatkan aplikasi ecommerce pengusaha dapat lebih memasarkan produknya ke semua wilayah yang terjangkau oleh internet.

5) Mengurangi beban perusahaan dalam hal biaya promosi produk Perusahaan. Karena dengan adanya aplikasi e-commerce, pengusaha dapat langsung mempromosikan produknya dengan lebih cepat dan efisien.

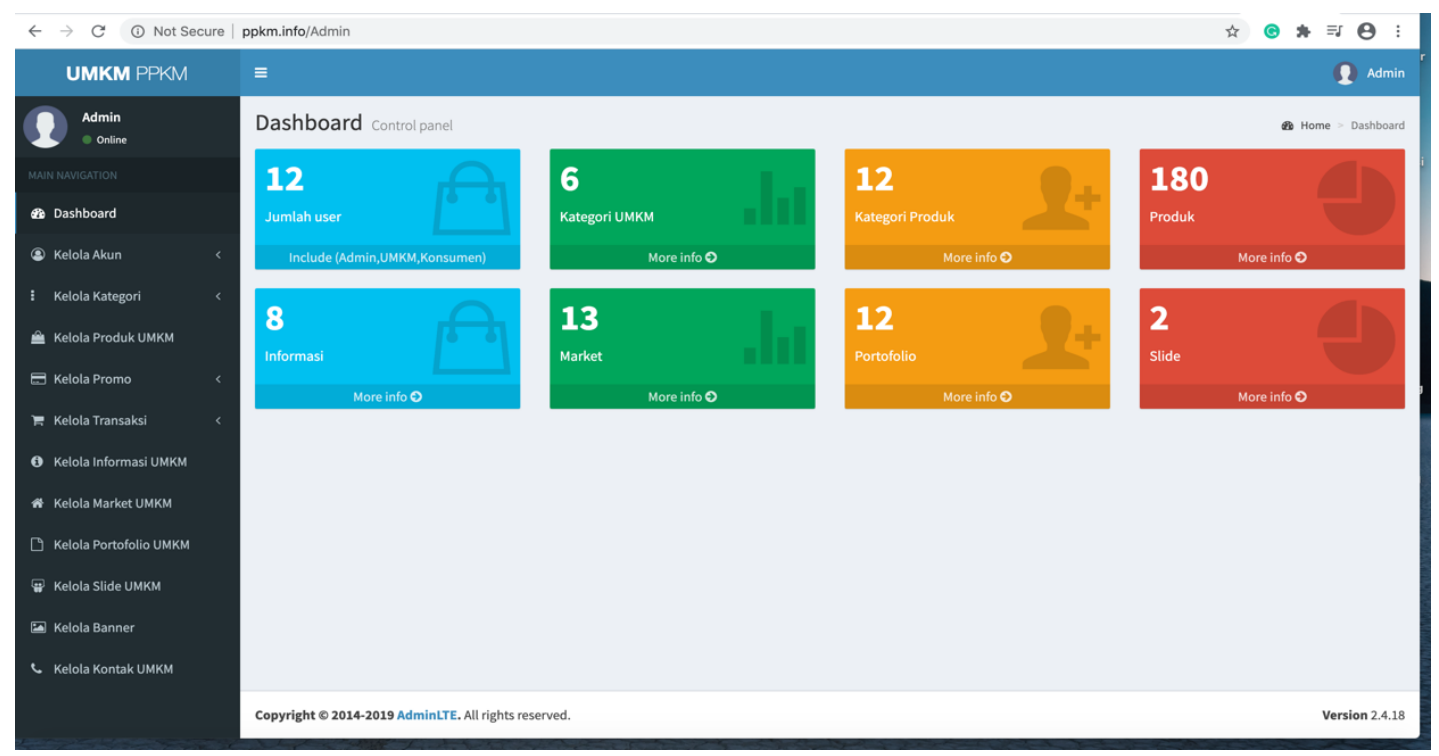

Gambar 3

Halaman Dashboard Web PPKM 

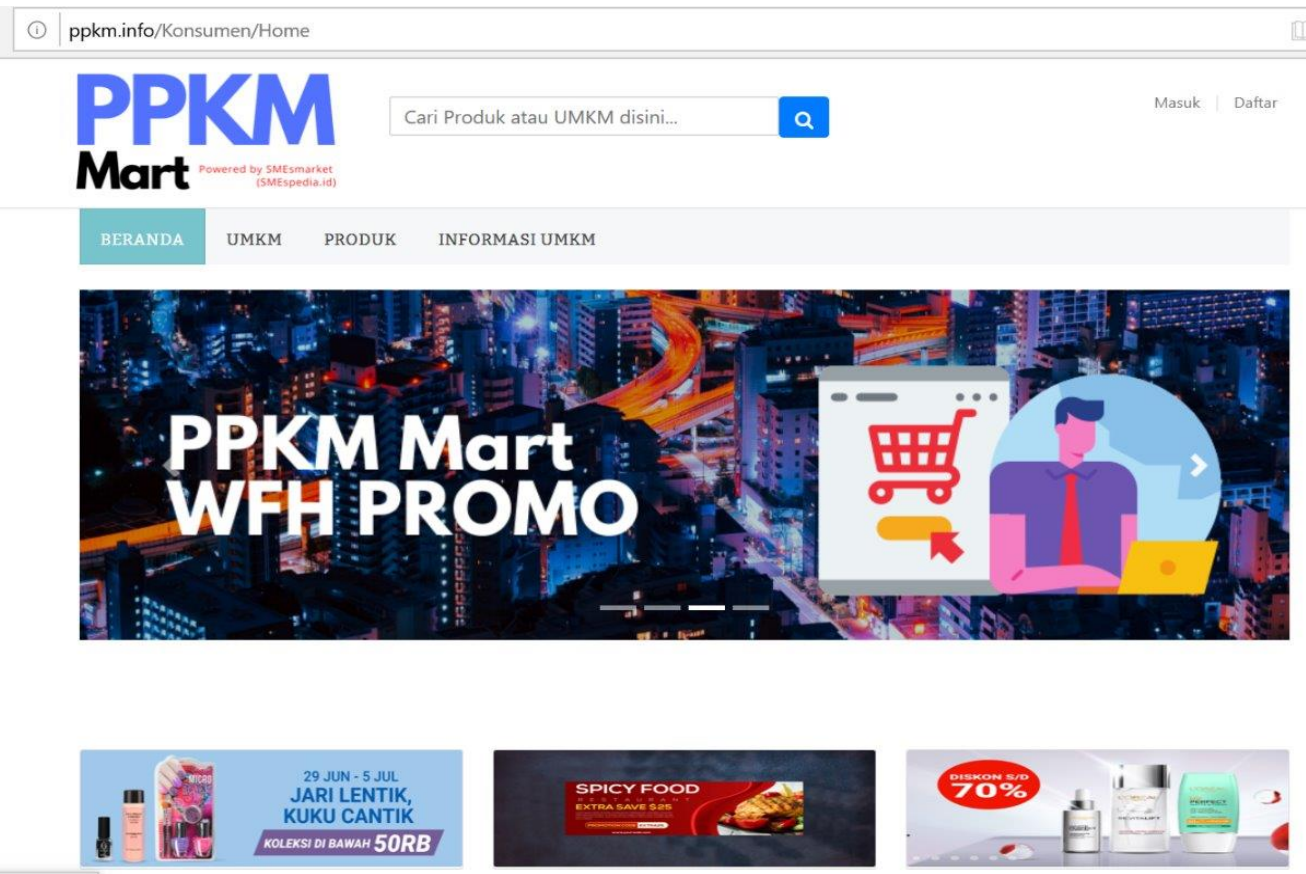

Gambar 4

Halaman Beranda Web PPKM

Pada Gambar 3, menjelaskan beranda PPKM yang berisi tentang tampilan halaman serta akses halaman yang dapat menampilkan topik fitur pada web http://ppkm.info/Konsumen/Home.

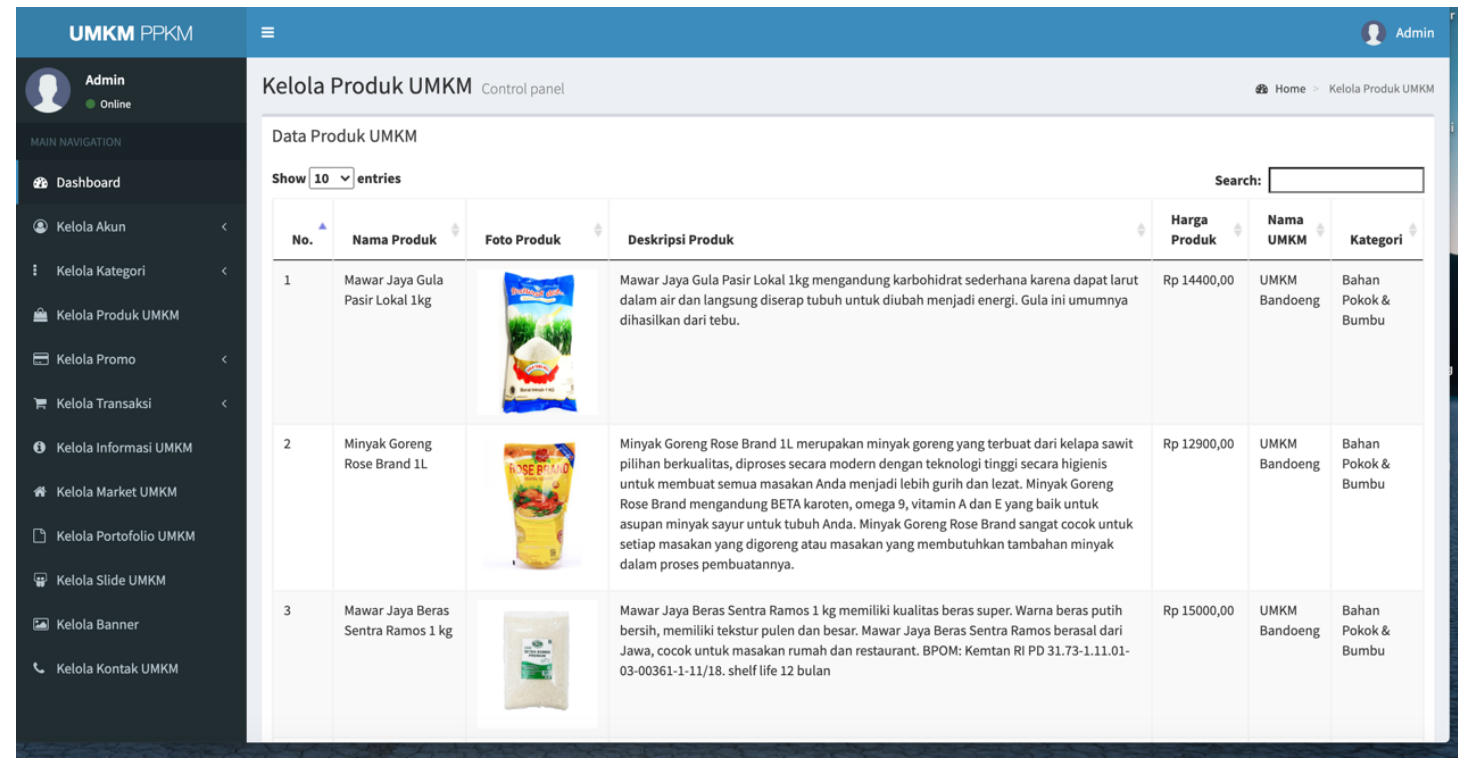


Gambar 5

\section{Halaman Fitur Produk UMKM - PPKM}

Pada Gambar 4, menjelaskan beranda fitur produk yang di tawarkan oleh UMKM-PPKM yang berisi tentang tampilan halaman produk-produk yang di pasarkan secara online berikut keterangan harga, produk asal, serta informasi lain yang terkait dengan produk.

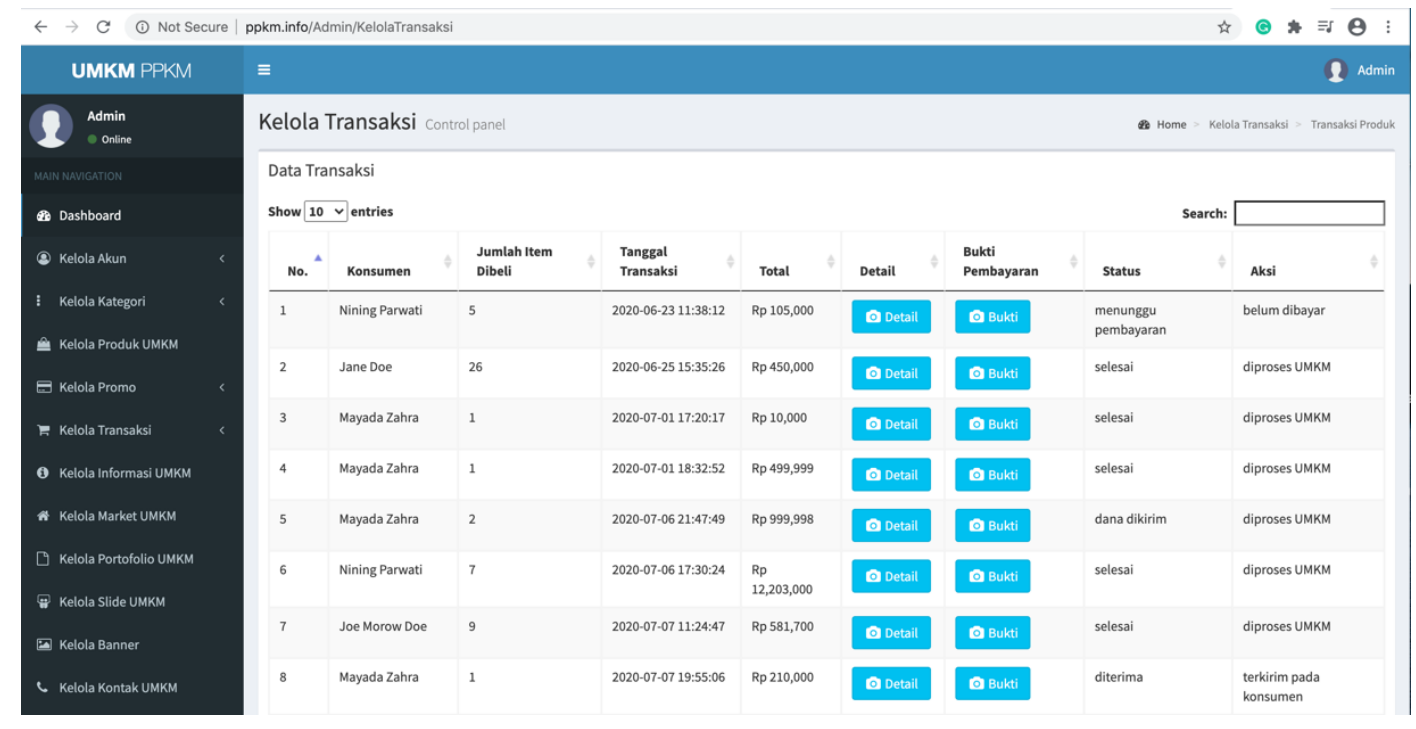

\section{Gambar 6}

Halaman Pengelolaan Jenis Transaksi UMKM-PPKM

Pada ganbar 5, menjelaskan fitur dan informasi yang terkait pembelian yang dilakukan oleh konsumen berikut rincian serta penjelasan sehingga proses pembayaran serta pengiriman dapat diawasi dan terkontrol dengan jelas. 


\section{Porm}

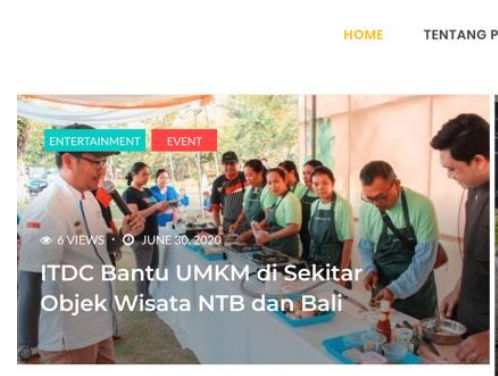

BERITA EVENT

KATALOG PPKM

GALLERY

CONTACT US JOIN PPKM

$\theta \quad a \equiv$
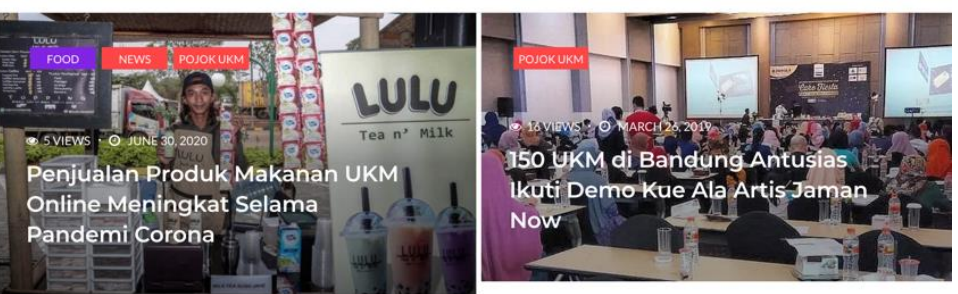

Gambar 7

Halaman Utama Web PPKM

Pada Gambar 4 menunjukkan halaman utama website PPKM, yang berisi menu yang disediakan oleh web PPKM. Pada halaman utama ini juga menampilkan kegiatan yang berkaitan dengan UMKM

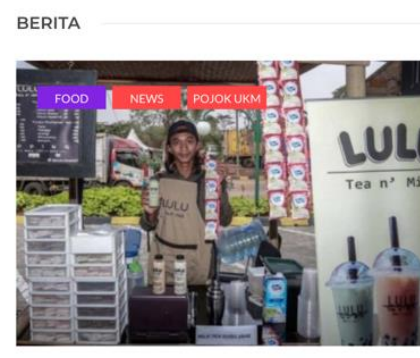

Penjualan Produk Makanan UKM Online Meningkat Selama Pandemi Corona

Jakarta - Pandemi corona secara tidak langsung membuat penjualan produk kuliner meningkat. Menurut Menteri Koperasi dan UKM, Teten Masduki, para

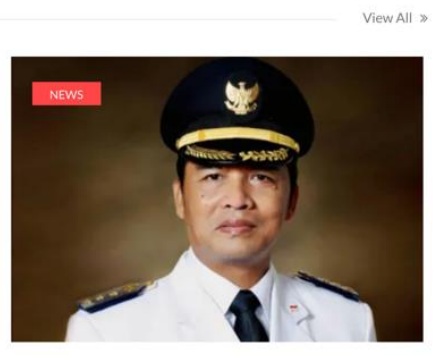

Bupati Bandung Dukung Penuh UKM Lokal Bandung

Sed ut perspiciatis, unde omnis iste natus error sit voluptatem accusantium doloremque laudantium, totam rem aperiam eaque ipsa,

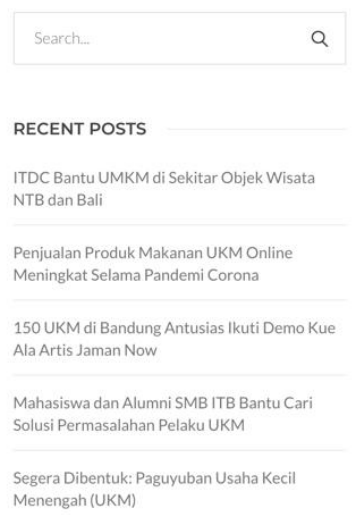

Gambar 8 Halaman Berita PPKM

Pada gambar 5 diatas menunjukkan halaman khusus terkait berita yang berkaitan dengan UMKN. Halaman ini sangat dibutuhkan oleh pihak UMKN karena terkait dengan informasi terbaru terkait dengan UMKN dalam meningkatkan proses unit bisnisnya. 


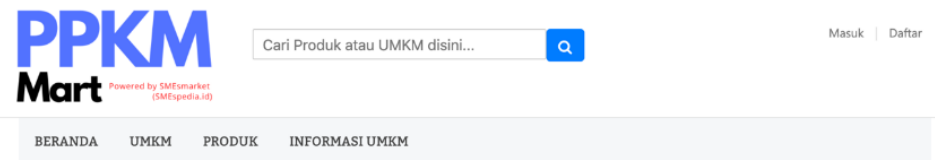

Masuk atau Daftar Akun

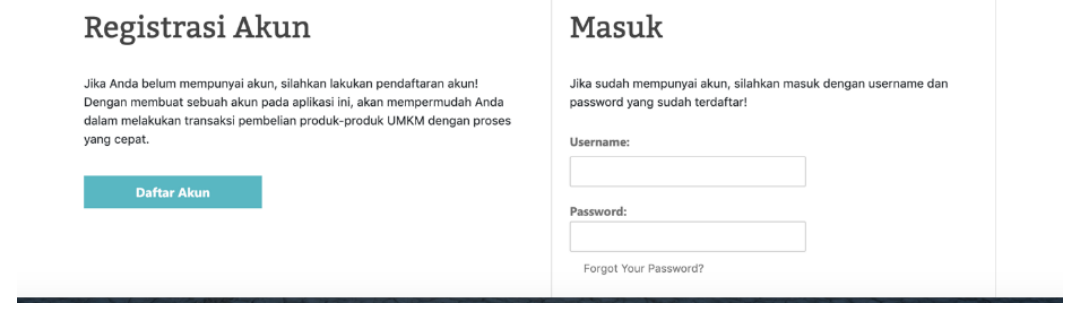

Gambar 9

Halaman Registrasi Akun PPKM

Pada gambar 6 diatas merupakan halaman yang disediakan untuk proses authentikasi untuk akun yang sudah terdaftar dan halaman pendaftaran akun bagi akun yang baru. Halaman ini disediakan untuk mempermudah user dalam melakukan transaksi produkproduk UMKN.

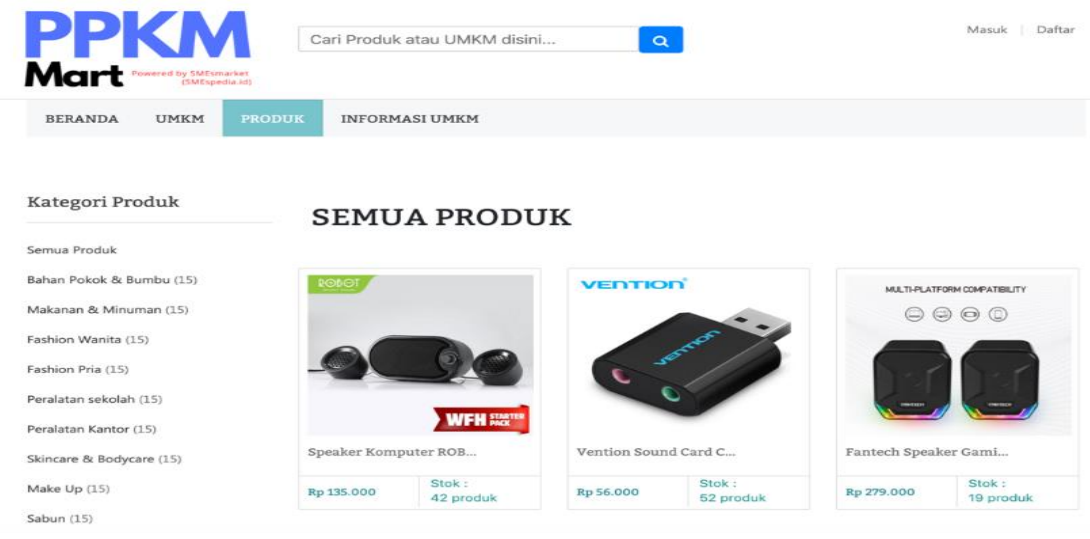

\section{Gambar 10 \\ Halaman E-Katalog Produk UMKM - PPKM}

Pada gambar 6 diatas menunjukkan tampilan dari informasi produk-produk yang ditawarkan oleh pihak UMKM. Melalui halaman ini pengusaha UMKM dapat melakukan promosi produknya dengan lebih mudah dan lebih baik. Selain itu melalui halaman ini pun pembeli dapat melakukan pencarian dan pembelian produk UMKM dengan mudah. 

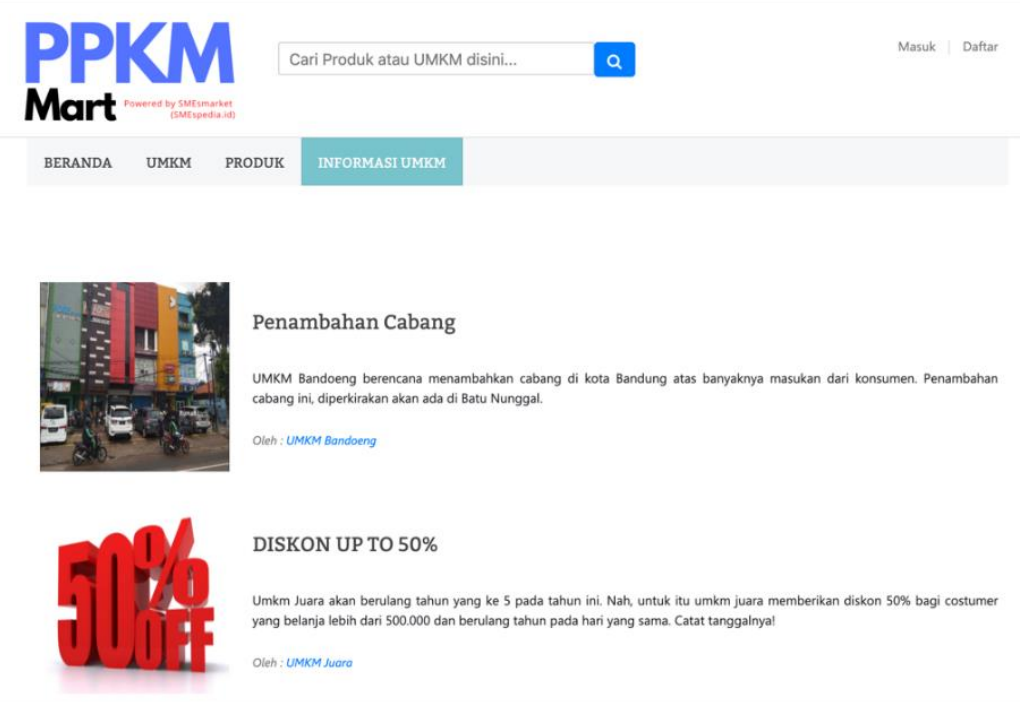

\section{Gambar 11 \\ Halaman Informasi - PPKM}

Pada Gambar 8 diatas menunjukkan informasi umum yang disediakan oleh pihak UMKN kabupaten Bandung, sehingga semua kegiatan UMKM dapat lebih mudah di informasikan ke semua user.

\section{KESIMPULAN \& SARAN}

Kegiatan pengabdian masyarakat yang dilakukan terhadap mitra PPKM (Paguyuban Pengusaha Karsa Mandiri) menghasilkan sistem pemasaran online berupa website e-commerce dengan fitur utama berupa katalog produk dan transaksi online serta memberikan pelatihan terhadap penggunaan website tersebut. Hal tersebut mampu membantu pelaku usaha pada PPKM (Paguyuban Pengusaha Karsa Mandiri) untuk memperluas jangkauan pemasaran dan mampu meningkatkan efisiensi proses bisnis serta biaya promosi. Selain itu, website e-commerce yang dibangun pada kegiatan pengabdian masyarakat ini mampu memberikan peluang positif bagi UMKM ditengah kondisi pandemi COVID-19. Pemasaran dan transaksi dapat dilakukan secara online sehingga UMKM dapat tetap menjalankan usahanya meskipun ada pembatasan aktivitas di luar rumah.

Sebagai saran, program ini perlu adanya tindak lanjut, sehingga bisa tetap berkelanjutan dan harapannya bisa mendapatkan pendanaan dari pemerintah. Selain itu, pemerintah diharapkan senantiasa melindungi para pelaku usaha kecil yang mempunyai keinginan naik kelas di bidang bisnisnya dengan mengendalikan produk impor yang masuk agar tidak mematikan usaha lokal. 


\section{DAFTAR PUSTAKA.}

Gangeshwer, D. K., (20130., "E-Commerce or Internet Marketing: A Business Review from Indian Context", International Journal of u- and e- Service, Science and Technology Vol.6, No.6 pp.187-194.

Handayani, Sri, dkk. (2016). Sistem Informasi E-Commerce Untuk Jaringan Penjualan Sepeda Motor Bekas Kabupaten Kampar (Studi Kasus Adira Finance). Jurnal Rekayasa Dan Manajemen Sistem Informasi. Vol. 2. No 2. Agustus 2016.

Irnawati, Dewi, (2011)., "Pemanfaatan E-Commerce Dalam Dunia Bisnis, Jurnal Ilmiah Orasi Bisnis, Edisi Ke-VI, November 2011.

Kotler, Philip and Kevin Lane Keller. (2016). Marketing Management. 15e New jersey: Person Prentice Hall, Inc.

M, Niranjanamurthy dkk, (2013)., "Analysis of E-Commerce and M- Commerce: Advantages, Limitations and Security issues", International Journal of Advanced Research in Computer and Communication Engineering Vol. 2, Issue 6, June 2013.

Maryama, Siti. (2013). Penerapan E- Commerce Dalam Meningkatkan Daya Saing Usaha. Jurnal Liquidity. Vol. 2. No. 1. Januari-Juni 2013.

Shabur, Miftah Maulana, dkk. (2015). Implementasi E-Commerce Sebagai Media Penjualan Online (Sudi Kasus Pada Toko Pastbrik Kota Malang). Jurnal Administrasi Bisnis. Vol. 29 No. 1 Desember 2015. 